\title{
Equipment
}

\section{Flow velocity profile of the pulmonary artery measured by the continuous cardiac output monitoring catheter}

Keiko Miyasaka MD, Masao Takata MD, Katsuyuki Miyasaka MD
$0.49 \pm 0.26$ from $S_{l}$ to $S_{5}$, i.e., lower in $S_{l}$ and $S_{5}$ which were close to the vascular walls $(P<0.05)$ but uniform in other areas. Along the long axis, flow velocity was $0.28 \pm 0.28$, $0.88 \pm 0.09,0.94 \pm 0.08,1.06 \pm 0.25$ and $1.28 \pm 0.50$ from $L_{1}$ to $L_{5}$. Thus, flow velocity was lower in $L_{l}$ which was close to the bifurcation $(P<0.05)$, slightly higher in $L_{5}$ close to the pulmonary valve, but uniform in other areas. These results suggest that the profile of blood flow velocity is relatively uniform within the main PA except in areas close to the vessel walls or valve. We conclude that movement of the catheter within the vessel would not substantially influence the accuracy of the KATS catheter system as long as the flow velocity sensor of the catheter stays within the main PA.

La sonde KATS (Continuous Arterial Thermodeprivation Systems), en calculant par déperdition thermique la vitesse de l'écoulement sanguin dans l'artère pulmonaire $(A P)$, mesure le débitcardiaque. La précision du système peut dépendre de la constance de la vélocité sanguine dans l'AP, les battements cardiaques rendant inévitables de petits mouvements de la sonde. Pour évaluer cette source potentielle d'erreurs, nous avons mesuré le profil de la vélocité de lécoulement sanguin sur sept chiens anesthésiés, à thorax ouvert. Nous avons intégré le senseur de vélocité de courant d'une sonde KATS à un cathéter rigide, créé sur mesure, dans le but de pénétrer l'AP principale perpendiculairement à la direction du flux sanguin (axe court) ou parallèlement à sa direction (axe long). Le cathéter rigide a été avancé par paliers de $2,5 \mathrm{~mm}$ et la vélocité du flux mesurée. Nous avons établi la moyenne les données et les avons présentées comme des valeurs relatives en regard d'un point-contrôle central. Sur l'axe court, la vélocité du courant a été de 0,41 $\pm 0,20$ (SD), de 1,00 $\pm 0,01$, de 1,03 \pm 0,01 , de 1,08 $\pm 0,13$ et de $0,49 \pm 0,26$, des points $S_{1} \grave{a} S_{5}$ respectivement; donc plus basse à $S_{l}$ et $S_{5}$ qui sont les points les plus rapprochés des parois vasculaires $(P<0,05)$ mais uni- 
forme dans les autres zones. Parallèlement, à l'axe long, la vélocité était de 0,28 $\pm 0,28$, de 0,88 $\pm 0,09$, de 0,94 $\pm 0,08$, de $1,06 \pm 0,25$, et de $1,28 \pm 0,50$ de $L_{l}$ à $L_{5}$. La vélocité du courant était donc moindre à $L_{l}$, lequel est situé près de la bifurcation $(P<0,05)$, légèrement plus grande à $L_{5}$ près de la valve pulmonaire, mais uniforme dans les autres zones. Ces résultats suggèrement que le profil de la vélocité de l'écoulement sanguin est relativement uniforme dans l'AP principale à l'exception des points situés à la proximité des parois et de la valve. Nous concluons que les mouvements de sonde dans un vaisseau ne devraient pas influencer de façon appréciable la précision du système de sondes KATS aussi longtemps que le senseur de vélocité reste dans l'artère pulmonaire principale.

In 1991 we developed a modified pulmonary artery catheter (continuous arterial thermodeprivation system catheter; KATS catheter) which is capable of continuous monitoring of cardiac output by thermodeprivation. ${ }^{1} \mathrm{~A}$ specially designed thermistor (KATS thermistor) is incorporated into the tip of the catheter along with the usual thermistor for conventional thermodilution cardiac output measurement. The KATS thermistor, heated by a constant, low electric current, is cooled by blood flow around it. Since the degree of thermodeprivation, as detected by a decrease in temperature of the thermistor, is proportional to the blood flow velocity around it, the KATS thermistor can continuously measure blood flow velocity in the pulmonary artery (PA). Cardiac output can be continuously calculated from the temperature signal of the KATS thermistor, once the value of the crosssectional area is derived from a single-point thermodilution measurement. It is assumed that the cross-sectional area of the PA is constant.

The accuracy of the KATS catheter system in a clinical setting depends on the uniformity of blood flow velocity in the PA. Small movement of the catheter tip within the PA, inevitable in an in vivo beating heart, may produce errors in cardiac output calculation if there is uneven distribution of flow velocity within the PA. The profile of blood flow velocity in the PA was measured by use of the KATS thermistor in acutely instrumented open chest dogs to assess these potential errors.

\section{Methods}

\section{Surgical preparation}

The experimental study was approved by the Institutional Animal Care and Use Committee. Seven mixed-breed dogs weighing 11.0-15.5 kg were anaesthetized with pentobarbitone sodium (30 $\left.\mathrm{mg} \cdot \mathrm{kg}^{-1} i v\right)$, their tracheas intubated, and their lungs ventilated with a pressure-preset

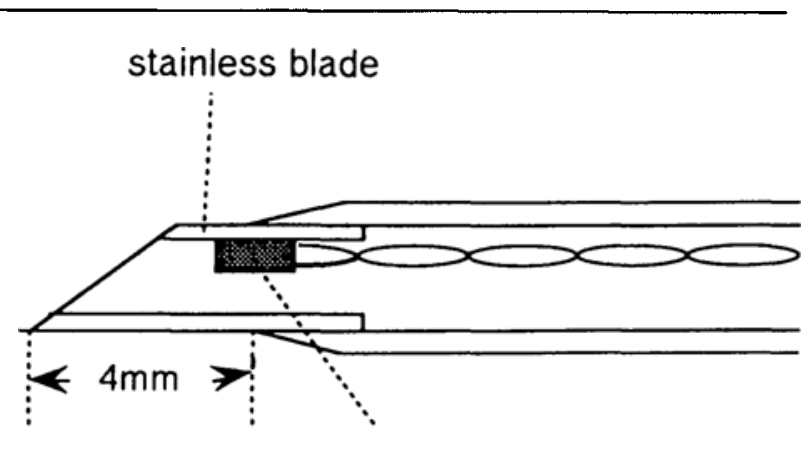

KATS thermistor

FIGURE 1 Schematic diagram of the custom-made stiff catheter to penetrate the PA.

time-cycled ventilator (Newport E100, Newport Medical Inc. Ca). Anaesthesia was maintained by bolus intravenous injections of pentobarbitone. Ventilator settings were adjusted to maintain arterial blood gases within the normal range. A large-bore catheter was placed in a femoral vein for injection of drugs and fluids. A polyethylene catheter was advanced via a femoral artery into the thoracic aorta for measurement of arterial pressure and sampling of blood gases. A left thoracotomy was performed, and the pericardium was opened via a longitudinal incision. An electromagnetic flow probe (Model VE, Nihon Kohden, Japan) was placed around the root of the ascending aorta to measure aortic blood flow. The main pulmonary artery was exposed from the pulmonary valve to the bifurcation.

\section{Blood flow velocity measurement}

To measure the profile of blood flow velocity in the main PA, we used a custom-made stiff catheter with a KATS thermistor at the tip (Figure 1). The stiff catheter was $0.7 \mathrm{~mm}$ in diameter and $150 \mathrm{~mm}$ in length. A KATS thermistor was incorporated into the tip of the catheter and covered by a sharp stainless needle. The main PA was penetrated with the stiff catheter and flow velocity within the PA was determined by the temperature signal from the KATS thermistor. As described previously, ${ }^{1}$ when a KATS thermistor is heated by a constant electric current, the relationship between its temperature $(T)$ and blood flow velocity around it (v) can be approximated by,

$\log \mathrm{T}=\mathrm{a} \log \mathrm{v}+\mathrm{b}$

where " $a$ " and " $b$ " are constants for this particular thermistor defined by in vitro experiments (Figure 2). With this empirically obtained logarithmic equation, the flow velocity at a certain point within the PA can be calculated. The profile of flow velocity along that direc- 


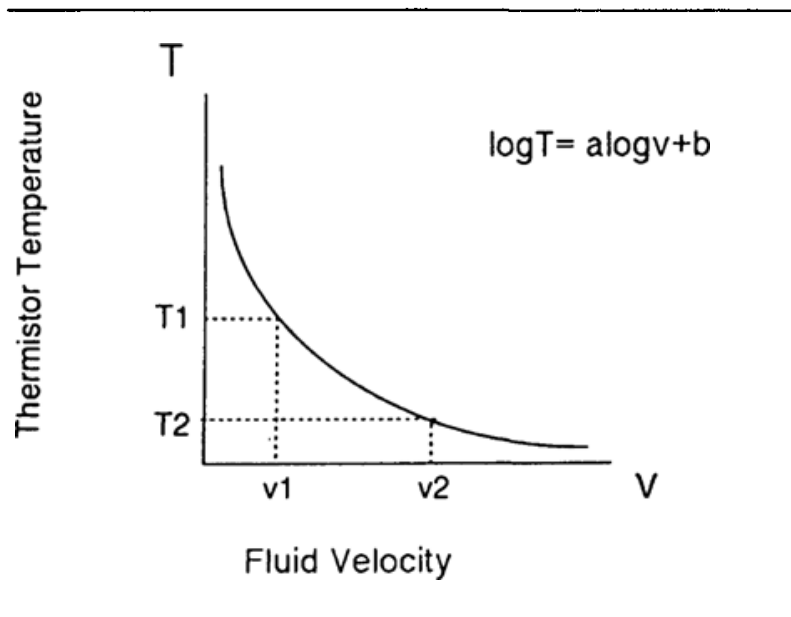

FIGURE 2 Relationship between the temperature ( $T$ ) of the KATS thermistor and blood flow velocity (v). Constants " $a$ " and " $b$ " for a particular thermistor are defined by in vitro experiments.

tion can be obtained by moving the stiff catheter and the KATS thermistor in increments along a certain axis of the PA if pulmonary blood flow and cardiac output are unchanged during the procedure.

\section{Protocols}

The main PA was penetrated with the stiff catheter in two orthogonal directions (Figure 3): (1) in the short axis direction $(n=7)$, i.e., perpendicular to the blood flow direction in PA. The catheter was inserted from a point $1 \mathrm{~cm}$ distal to the pulmonary valve and advanced until the tip of the catheter reached the opposite vessel wall, and (2) in the long axis direction $(n=6)$, i.e., along the blood flow direction in PA. The catheter was inserted from a point $0.5 \mathrm{~cm}$ distal to the pulmonary valve and advanced until the tip reached the bifurcation of the PA. A purse-string suture was placed at the point of insertion to prevent bleeding. The wall-to-wall distance between the insertion point and the opposite vessel wall or bifurcation was measured by graduated $2.5 \mathrm{~mm}$ markers on the catheter. The catheter was pulled to the middle of the PA and the temperature of the thermistor was recorded to calculate the control mid-point flow velocity in that direction. The catheter was then advanced to the opposite vessel wall or bifurcation and gradually pulled out in increments of $2.5 \mathrm{~mm}$ toward the insertion point. The temperature of the thermistor was recorded at each point. Electrocardiogram, arterial pressure, and aortic blood flow were monitored to confirm that a steady state with an unchanged cardiac output was approximated during each procedure.

\section{Data analysis}

Flow velocity data were calculated from the temperature

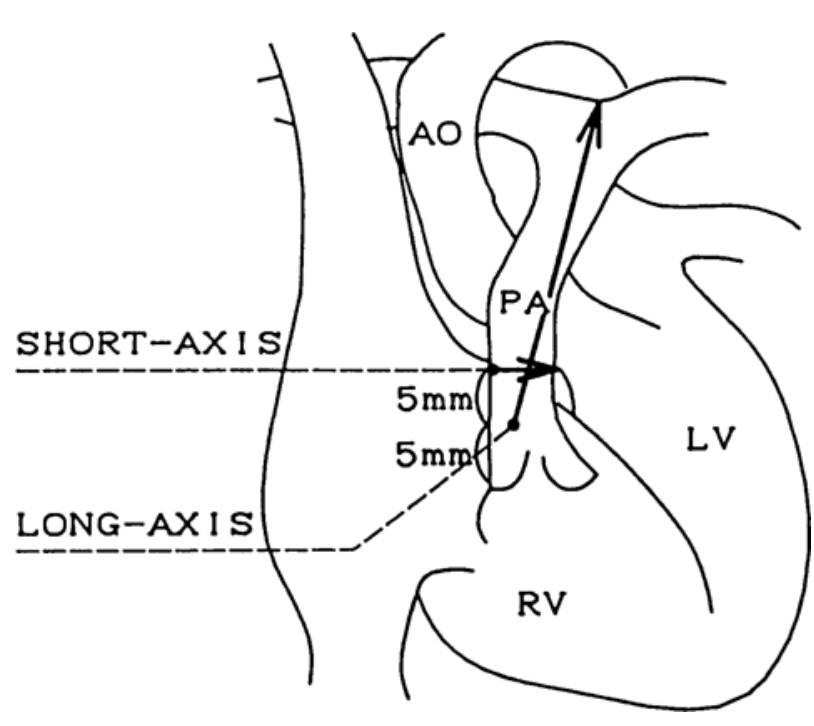

FIGURE 3 A schematic illustration showing short and long axis directions to penetrate PA. Ao, aorta; LV, left ventricle; RV, right ventricle.

signal of the KATS thermistor according to the equation described above and presented as relative values against the control mid-point flow velocity value in each axis direction. The wall-to-wall distance along each direction was divided into five sections, i.e, $S_{1}$ to $S_{5}$ for the short axis, and $\mathrm{L}_{1}$ to $\mathrm{L}_{5}$ for the long axis. The flow velocity data within each section were grouped and averaged. Data from all dogs are expressed as mean \pm SD. Statistical comparisons were made by one-way analysis of variance (ANOVA) for repeated measures and Scheffe's test. An alpha error less then 0.05 was considered significant.

\section{Results}

The results from all dogs are summarized in Figure 4 and Figure 5. Along the short axis, flow velocity was lower in $S_{1}$ and $S_{5}$ where the thermistor was very close to the vessel wall $(P<0.05)$, but uniform among the other three central sections. Along the long axis, flow velocity was lower in $\mathrm{L}_{1}$, which was close to the bifurcation $(P<0.05)$. Flow velocity showed a small but statistically insignificant increase in $\mathrm{L}_{5}$ close to the pulmonary valve. Flow velocity was uniform in the other three sections.

\section{Discussion}

Although measurement of cardiac output by thermodilution is common in clinical practice, ${ }^{2-4}$ it has several limitations in the management of critically ill patients. It can provide only intermittent data, and frequent injections of cold saline may cause problems such as fluid 


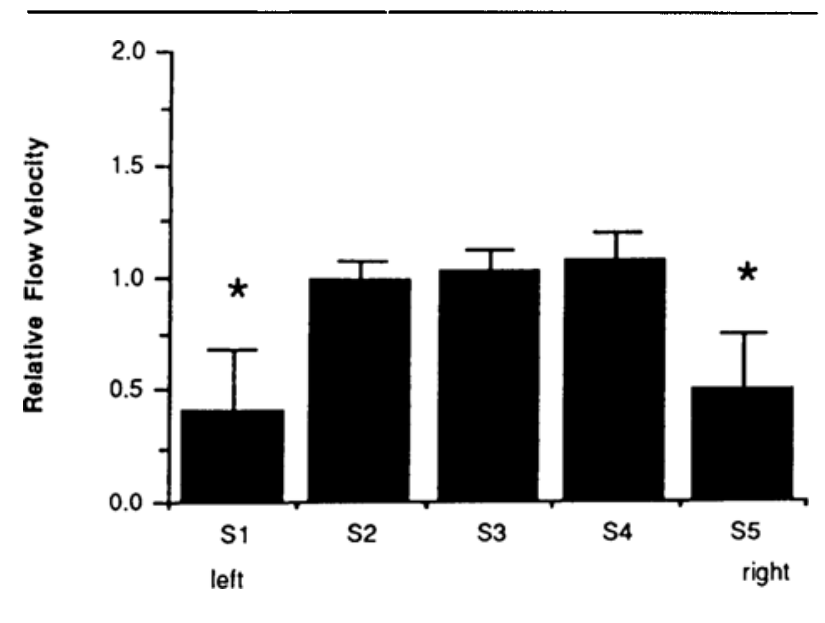

FIGURE 4 Flow velocity profile in the main PA along the short axis direction $(n=7)$. Flow velocity data are presented as relative values against the control mid-point flow velocity value. The wall-to-wall distance along the axis was divided into five sections from $S_{1}$ to $S_{5} . S_{1}$ and $S_{5}$ represent the areas close to the left and right walls of the main PA, respectively. $P<0.05$, significantly different from the other three sections by one way ANOVA and Scheffe's tests.

overload, hypothermia, or bacterial contamination. The KATS catheter was developed to overcome these limitations. ${ }^{1}$ It is capable of continuous monitoring of cardiac output while fully preserving the function of conventional thermodilution. This system has been introduced into clinical practice and is now used in patients of all ages, from infants to adults, in Japan. The present study experimentally evaluated possible errors of the KATS catheter system due to movement of the catheter tip within the PA.

Our results showed that flow velocity within the main $\mathrm{PA}$, as determined by thermodeprivation, is quite uniform, except in areas close to the vessel wall or valve. Several studies have measured the flow velocity profile of the PA. Reuben et al. reported that the velocity profile measured by the thin-film technique was flat in dogs, and was almost uniform with a slightly lower velocity close to the posterior wall in humans. ${ }^{5}$ Paulsen utilized a hot-film anemometer in dogs and found that the velocity profile in the PA was approximately uniform with a slightly higher velocity near the posterior wall. ${ }^{6}$ Our results are consistent with these findings which were derived by quite different techniques. The influence of rheological factors in the PA in a particular experimental condition, e.g., degree of acceleration or deceleration of flow, shape of the PA (converging, diverging, or curved), and blood viscosity, may explain the somewhat lower or higher flow velocities in the areas close to the vessel wall found in each study. ${ }^{\text {? }}$

The results imply that movement of the KATS

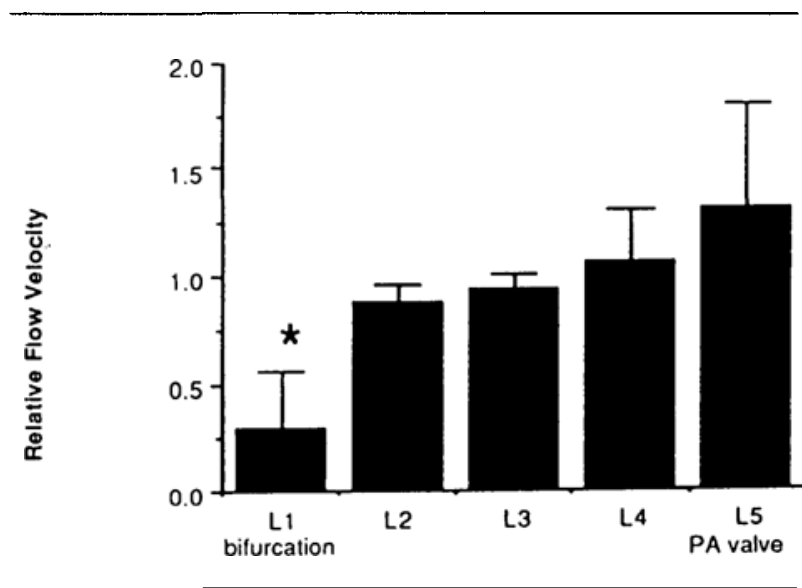

FIGURE 5 Flow velocity profile in the main PA along the long axis direction $(n=6)$. Flow velocity data are presented relative to the control mid-point velocity values. The wall-to-wall distance along the axis was divided into five sections from $L_{1}$ to $L_{5} . L_{1}$ represents the areas close to the bifurcation, and $\mathrm{L}_{5}$ represents the area close to the pulmonary valve. ${ }^{*} P<0.05$, significantly different from the other sections by one way ANOVA and Scheffe's tests.

thermistor in most portions of the main PA would not produce large changes in the flow velocity signal, unless the thermistor closely approached the vessel wall, bifurcation, or valve. Several other factors may influence the overall accuracy of the KATS catheter system when it is used in actual clinical practice. Changes in body position, measurement of pulmonary wedge pressure, or acute injection of fluid via the catheter lumen may produce dislocation of the catheter. Changes in ventilation may produce changes in the cross-sectional area of the pulmonary vasculature. Although the influence of these factors remains to be evaluated by assessing this system in clinical settings, the results of the present study strongly suggest that movement of the KATS catheter within the vessel would not substantially influence the accuracy of the system, as long as the thermistor is placed within the main PA.

\section{Acknowledgements}

The authors would like to thank $\mathbf{K}$. Tsuchida and S. Sekii from Terumo for their technical assistance.

\section{References}

1 Miyasaka $K$, Volgyesi G, Katayama $M$, Tanabe $S$. Continuous cardiac output determination by thermodeprivation. Journal of Anaesthesia 1991; 5: 205-12.

2 Swan HJ, Ganz W, Forrester J, Marcus H, Diamond G, Chonette $D$. Catheterization of the heart in man with use of a flow-directed balloon tipped catheter. $\mathrm{N}$ Engl J Med 1970; 283: 447-51.

3 Ganz W, Donoso R, Marcus HS, Forrester JS, 
Swan HJ. A new technique for measurement of cardiac output by thermodilution in man. Am J Cardiol 1971; 27: 392-6.

4 Weisel RD, Berger RL, Hechtman HB. Measurement of cardiac output by thermodilution - current concepts. N Engl J Med 1975; 292: 682-4.

5 Reuben SR, Swadling JP, Lee GJ. Velocity profiles in the main pulmonary artery of dogs and man, measured with a thin-film resistance anemometer. Circ Res 1970; 27: 995-1001.

6 Paulsen PK. The hot-film anemometer - a method for blood velocity determination. II. In vivo comparison with the electromagnetic blood flowmeter. Eur Surg Res 1980; 12: $149-58$.

7 Hatle L, Angelsen B. Physics of blood flow, doppler ultrasound in cardiology. In: Hatle L, Angelsen B (Eds.). Physical Principles and Clinical Application. 2nd ed. Philadelphia: Lea and Febiger, 1985; 8-31. 